\title{
Segmentação Psicográfica: quais os métodos mais eficazes em pesquisas de mercado?
}

\author{
Marcelo Costa de Souza \\ Universidade Fumec - Brasil \\ marcelo-souza1972@hotmail.com \\ http://orcid.org/oooo-0oo2-3903-9741 \\ José Marcos de Carvalho Mesquita \\ Universidade Fumec- Brasil \\ jose.mesquita@fumec.br \\ http://orcid.org/oooo-ooo1-5897-1537
}

\begin{abstract}
Resumo
Entende-se a análise psicográfica como método diferenciado em mapear as inclinações de consumo e maximizar o retorno das ações de marketing, a qual aumenta em importância face à maior complexidade do ambiente contemporâneo. Isto posto o objetivo do artigo foi criar um instrumento de referência em técnicas psicográficas para futuras pesquisas, por meio do estudo sistemático comparativo dos principais modelos psicográficos empregados em pesquisas de mercado. Pretende-se contribuir no processo de utilização de técnicas que sejam mais adequadas às demandas específicas de segmentação. $\mathrm{O}$ estudo realizado credita à melhor escolha e emprego dos modelos psicográficos um meio de tornar as pesquisas para segmentação mais eficazes. A metodologia empregada no artigo implicou na apreciação crítica dos principais modelos da segmentação de base psicográfica AIO, RSV, VALS, LOV e 3M. Como resultado, estabeleceu-se um quadro-sintético de comparativo técnico, o qual foi precedido de análise teórica. Acredita-se que o conteúdo do quadro teórico sirva para guia no processo de seleção e utilização dos diversos métodos, visando ao maior ajustamento do uso de modelos psicográficos aos diferentes contextos ambientais, e, assim, favorecer aplicações de pesquisas de mercado.
\end{abstract}

Palavras-Chave: segmentação psicográfica, personalidade, valores, estilos de vida. 


\title{
Psychographic segmentation: what are the most effective methods in market research?
}

\author{
Marcelo Costa de Souza \\ Universidade Fumec - Brasil \\ marcelo-souza1972@hotmail.com \\ http://orcid.org/oooo-0oo2-3903-9741 \\ José Marcos de Carvalho Mesquita \\ Universidade Fumec- Brasil \\ jose.mesquita@fumec.br \\ http://orcid.org/oooo-ooo1-5897-1537
}

\begin{abstract}
We understand the psychographic analysis as a different method of mapping the propensities of consumption and maximize the return on marketing activities, which increases in importance given the greater complexity of the contemporary environment. Thus, the purpose of the article was to create a reference tool for psychographic techniques for future research, through comparative systematic study of the major models used in psychographic market research. We intend contribute to the process of using techniques that are most appropriate to the specific segmentation requirements. The study credits to the best choice and use of psychographic models a way of making segmentation research more effective. The methodology involved the critical appraisal of the main models of psychographic segmentation: AIO, RSV, VALS, LOV and $3 \mathrm{M}$. As a result, we established a synthetic framework of technical comparison, which was preceded by theoretical analysis. We believe that the contents of the theoretical framework will serve to guidance in selection and use of various methods, aimed at further alignment of using psychographic models to different environmental contexts, and thus favoring market research applications.
\end{abstract}

Keywords: psychographic segmentation, personality, values, life styles. 


\section{Introdução}

O mercado global, patrocinado pelo acelerado avanço tecnológico vivenciado nas últimas décadas, vem conduzido profundas transformações, impondo às empresas e seus gestores "novos tempos". Com isso, profissionais de marketing são remetidos a incessantes desafios em suas decisões, em meio a um ambiente mais competitivo, mutável e veloz que em décadas anteriores, e que, pelas incertezas crescentes, torna imprescindível uma compreensão mais aprofundada do comportamento de consumo.

Considerando tamanhas mudanças no cenário do marketing contemporâneo, impactado pelas tecnologias da informação e do conhecimento, as alterações de mercado crescem em velocidade exponencial. Trata-se de novos desafios e ferramentas em relação ao consumo, como mídias sociais, marketing verde, neuromarketing e tantos outros. Dessa forma, o conhecimento sobre o consumidor torna-se peça fundamental aos gestores de marketing, pois a segmentação passa a ser influenciada por uma complexa teia de fatores, o que exige uma leitura mais acurada de mercado.

Diante do exposto, atualmente, é imperativo promover pesquisas mais abrangentes do consumidor, visando maior eficácia nos processos de segmentação do mercado. Em consequência, as práticas de marketing tendem a se tornar mais efetivas, contando com maior foco de atuação e elevação das possibilidades de retorno (Miniard et al., 2005). A partir disso define-se o problema de pesquisa: quais são os métodos psicográficos mais eficazes para aplicação de uma pesquisa de mercado?

Desta forma, o artigo apresenta como objetivo a criação de um quadro-modelo comparativo entre os distintos métodos psicográficos, e, a partir disso, apresentar de forma organizada uma discussão sistemática quanto à eficácia e aplicabilidade de tais métodos como o resultado proposto pela pesquisa. O estudo será subsidiado pelo embate promovido entre os modelos teóricos com o arcabouço de algumas linhas individualmente tratadas. $\mathrm{O}$ tratamento dos pilares conceituais, os quais intitulam o trabalho, irá ocorrer por meio de confrontação teórica, a qual será organizada em três partes.

A primeira parte se constituirá de uma análise de toda evolução e conceito da segmentação psicográfica como meio de instrumentalização dos gestores. E ainda, serão 
abordados os constructos que servem de base para formação dos métodos psicográficos: estilos de vida, valores e personalidade.

A segunda parte constará do estudo dos principais métodos de segmentação psicográfica empregados na atualidade (AIO, RSV, VALS, LOV e 3M). Em termos didáticos, tais métodos serão discutidos separadamente por linhas de abordagem, sendo essas, também organizadas por estilos de vida, valores e personalidade. As primeira e segunda partes, utilizadas como base de dados para a pesquisa, compõem o item 2 - "Referencial Teórico".

A terceira parte retrata o embate entre os métodos de segmentação psicográfica, fruto de análise dos dados secundários obtidos pela revisão de literatura. Assim, promove-se a técnica de confrontação teórica, cujo tratamento gera o estudo comparativo de modelos psicográficos, sob a forma de um quadro-resumo conceitual, a constar no item 4 “Discussão de resultados”. Tal estudo esquemático estabelece uma forma de abordagem que, diferentemente de estudos anteriores, inclui simultaneamente e compara de forma organizada os principais métodos de segmentação psicográfica, contendo comentários críticos de suas aplicações, limitações, e, possíveis vantagens, ou não, entre os modelos estudados. Logo após, o quadro-resumo comparativo de modelos teóricos é utilizado como meio de análise pelos pesquisadores, a partir do qual os mesmos propõem critérios de bases para segmentação, visando facilitar processos de decisão na adoção de modelos psicográficos. Assim, o artigo propõe um recurso com vistas a orientar a adequação das análises psicográficas aos objetivos de pesquisas de marketing, ao que se espera constituir um referencial para estudiosos e gestores.

Espera-se como contribuição deste trabalho, ao investigar possíveis antagonismos ou a complementaridade entre os métodos revisitados, estimular futuras pesquisas com vistas ao emprego de testes empíricos comparativos entre os modelos psicográficos abordados, o que por enquanto ainda carece da realização de estudos aplicados em pesquisas nacionais.

\section{Referencial Teórico}

\section{Segmentação psicográfica - evolução e conceito}


Em função das mudanças constantes nos perfis de consumo, é reforçada a importância do conceito de segmentação como arcabouço teórico de instrumentalização dos gestores de marketing, os quais adotam ferramentas gerenciais com vistas a atender às necessidades dos consumidores.

Renovam-se as tendências do marketing no século XXI, como a ênfase na qualidade, valor e satisfação dos consumidores, desenvolvimento do relacionamento, marketing direto e pela internet. Mas, dentre todas essas, o consumidor é o agente responsável pelas maiores mudanças, pois invariavelmente, são as mudanças de comportamento das pessoas o que tem indicado novos rumos às práticas do marketing, elevando-se a necessidade de processos mais efetivos para a segmentação de mercado (Melo, 2013).

Segmentação é o processo de divisão do mercado em grupos homogêneos significativos (segmentos ou nichos). Por meio da segmentação, a empresa ajusta racionalmente o composto mercadológico para atender às necessidades específicas de um ou mais segmentos e aumenta, como consequência, sua eficácia junto às exigências diferenciadas de cada grupo específico de consumidores. Os mercados podem ser fracionados mediante características relativas às pessoas, grupos ou organizações que os compõem: segmentação geográfica, demográfica (por idade, sexo, renda, ciclo de vida da família ou etnia), psicográfica (personalidade, motivação e estilos de vida), por benefícios e por taxa de uso (quantidade comprada de um produto) (Samara \& Morsch, 2005).

A segmentação beneficia os processos de comunicação e posicionamento do produto a um público específico. Posiciona-se o produto de acordo com características importantes para o público-alvo, realiza-se a comunicação de acordo com esse posicionamento e escolhese a mídia que tenha esse mesmo perfil. $\mathrm{O}$ uso da segmentação pode ainda contribuir de outras formas, como desenvolver novos produtos, ou reposicionar os existentes (Tomanari \& Yanaze, 2001).

Ao longo do tempo, dentre as categorias de segmentação mais utilizadas, prevaleceu o uso da segmentação demográfica. Entretanto, as variáveis demográficas, embora fundamentais aos profissionais de marketing, tem apresentado limitações evidentes. Entender porque determinado indivíduo compra uma marca A, mas não a marca $\mathrm{B}$, compõe o grande desafio do marketing. Segundo Tomanari e Yanaze (2001, p. 3), “[...] saber que o consumidor de determinado produto pertence à classe $\mathrm{A}$, tem entre $25-29$ anos, é $70 \%$ do 
sexo feminino, já não é mais suficiente para definir suas estratégias de marketing”. Corroboram esses, Campomar e Gil (2006, p. 3): "No entanto, as pessoas podem compartilhar as mesmas características demográficas, mas ainda serem muito diferentes entre si (Solomon, 2002). É por esse motivo que identificar quem compra é importante, porém entender por que compram é essencial”.

Como forma de suprir antigas limitações da análise demográfica, há décadas surgiu o conceito de segmentação psicográfica. A vantagem conferida pela segmentação psicográfica é que essa promove uma investigação quantitativa mais ampla, abordando conjuntamente, características demográficas, o estilo de vida e a personalidade do consumidor. Por estilo de vida, entende-se a descrição do modo como as pessoas vivem, consomem e utilizam seu tempo. "O termo psicografia refere-se à ideia de descrever (grafia, representar graficamente) a caracterização psicológica (psico) dos consumidores” (Mowen \& Minor, 2006).

É importante ressaltar que, na segmentação psicográfica, a referência à personalidade assume papel relevante na compreensão do comportamento consumidor. A personalidade “[...] é a referência a um atributo ou característica da pessoa que causa alguma impressão nos outros [...]" (Karsaklian, 2004). Personalidade também pode ser definida como "a soma total das maneiras como uma pessoa reage e interage com os demais" (Robbins et al., 2012); ou ainda, "respostas consistentes aos estímulos ambientais. Ela é uma maquiagem psicológica individual única, que consistentemente influencia como a pessoa responde ao seu ambiente" (Tomanari \& Yanaze, 2001).

$\mathrm{Na}$ concepção dos estudos psicográficos, existe ainda outro constructo de fundamental relevância - o valor: "A base psicográfica de segmentação utiliza variáveis mais subjetivas, como personalidade, valores e/ ou estilos de vida para o processo de segmentação" (Medeiros \& Dantas, 2007, p. 3).

Sob o prisma da psicologia social, define-se valor como uma crença que guia ações e julgamentos por meio de objetivos e situações específicos, além de objetivos imediatos para estados de existência mais profundos. Internalizados, de forma consciente ou não, os valores se tornam um padrão de critérios que guia a ação e desenvolve e mantém atitudes em direção a objetos e situações, para justificar ações e atitudes pessoais e dos outros, para julgar moralmente a si e aos outros e para se comparar aos outros. Sendo assim, os valores servem para criar interação social e apoiar a racionalização de crenças, atitudes e 
comportamentos, sendo determinante nos dois últimos. Os valores são centrais tanto para a vida dos indivíduos quanto para a sociedade como um todo (Rokeach como citado em Mello et al., 2008).

No campo psicográfico, os valores representam as crenças dos consumidores sobre a vida e comportamentos aceitáveis. São mais estáveis que as atitudes, pois transcendem situações ou eventos, mais duradouros pelo fato de serem centrais na estrutura da personalidade. Dividem-se em valores pessoais (individuais) e sociais (institucionais, culturais, organizacionais). Os valores pessoais definem certos comportamentos, são como normas para o indivíduo. Os valores sociais quase se tornam estereótipos de um segmento de mercado ou de um grupo e definem o comportamento tido como referência à sociedade ou grupo (Miniard et al., 2005). Blamey e Braithwaite (1997) destacam a importância dos valores sociais, sobretudo, no momento em que o produto de interesse seja um bem de interesse social, o qual possa ser explorado como base para segmentação de mercado, como por exemplo, o enfoque no ecoturismo ou turismo sustentável. Grunert et al. (1995) destacam em sua pesquisa a importância dos valores familiares como modalidade cultural dentre os valores sociais. De acordo com Corneo e Jeanne (1994), não há dúvidas de que pela via dos valores sociais é que a socialização e a influência mútua tipicamente ocorrem no mundo real.

Ressalta-se que o ser humano, como ente social, tem nos valores da sociedade ou dos grupos de referência à influência em seus próprios valores pessoais. Tais valores sociais, uma vez que sejam internalizados e determinantes no comportamento individual, incorporam-se aos valores pessoais (Leão et al.,2007).

Na segmentação psicográfica, prepondera o papel dos valores pessoais como padrões ou critérios que influenciam as escolhas dos indivíduos, sugerindo o relacionamento dos valores com o comportamento (Almeida et al., 2010): “[...] parece bastante coerente que os valores pessoais dos indivíduos, sendo um constructo da psicologia social, entendido como aquele que guia os indivíduos em seus comportamentos em sociedade, tenham papel crítico em suas orientações de consumo [...]" (Mello et al., 2008, p. 4).

Esclarece-se a interface de ligação entre os valores com a personalidade e os estilos de vida: 
A razão para a segmentação psicográfica ter evoluído para o enfoque nos valores dos consumidores pode ser explicada pela durabilidade e estabilidade que esse constructo apresenta na estrutura da personalidade dos indivíduos e sua possível relação com estilos de vida específicos, incluindo comportamentos de consumo (Medeiros \& Dantas, 2007, p. 3).

Acrescenta-se ainda que o estilo de vida e a personalidade embora sejam conceitos diferentes, estão intimamente interligados. É improvável que, por exemplo, uma pessoa dotada de personalidade classificada como de baixa necessidade de excitação, tenha como estilo de vida uma ocupação voltada à especulação de mercado ou à prática de esportes radicais (Mowen \& Minor, 2006).

A segmentação psicográfica funciona como conceito multidimensional, que procura integrar as características mais subjetivas das pessoas, tais como os valores, atitudes, interesses, opiniões e personalidade (Yanaze, 2007).

\section{Principais modelos de segmentação psicográfica}

\section{Segmentação psicográfica pelos estilos de vida (AIO).}

Considerando estudos e constatações pouco conclusivas que correlacionaram os traços de personalidade dos consumidores ao comportamento de consumo, sem direcionar estratégias mercadológicas pertinentes, profissionais de marketing deixaram de focar testes de personalidade defendidos por psicólogos e passaram a desenvolver análise do estilo de vida. O estudo pelo estilo de vida vai além da classe social e da própria personalidade, descrevendo todo um padrão de ação e de interação com o mundo. Trata-se do resultado de uma ordenação de forças econômicas, culturais e sociais que contribuem para as qualidades humanas de uma pessoa (Samara \& Morsch, 2005, Miniard et al., 2005).

Na vida social moderna, a noção de estilo de vida assume um significado especial.

Quanto mais a tradição perde seu domínio, e quanto mais a vida cotidiana é reconstituída em uma dialética do local e do global, mais indivíduos são forçados a 
negociar escolhas de estilos de vida entre uma diversidade de opções (Giddens como citado em Lawson \&Todd, 2003).

Os estudos sobre estilos de vida tiveram sua origem na sociologia. Explicam ainda, que apesar da diferença entre a sociologia e o marketing, ambos estudam o comportamento humano e a teoria do marketing não pode deixar de considerar as influências sociais no comportamento de consumo. A partir disso é que o marketing pode buscar conceitos sociológicos, úteis na tentativa de analisar, compreender e prever o comportamento do consumidor (Finotti, 2004).

A pesquisa baseada no estilo de vida é referenciada pelo modelo AIO (atividades, interesses e opiniões). O AIO procede como segmentação por estilo de vida que visa avaliar as atividades das pessoas em termos de gasto de tempo, interesses, opiniões a respeito de si e do mundo ao seu redor, características como seus estágios de vida, renda e educação (Yanaze, 2007).

Os seguintes itens compõem o modelo AIO: 1. Atividades - ações manifestas usualmente observáveis, como lazer, trabalho e devaneio; 2. Interesses (por algum objeto, evento ou tópico) - grau de excitação que acompanha a atenção especial ou contínua sobre qualquer coisa. Podem ser instrumentais (em que o tópico de interesse é visto como um meio para um fim) e terminais (vistos como fins em vez de meios); 3. Opiniões - respostas verbais ou escritas que uma pessoa dá a uma situação de estímulo (podem ser ulteriormente categorizadas como crenças, atitudes ou valores) (Samara \& Morsch, 2005).

A análise psicográfica permite avaliar estilos de vida e ir além da demografia, podendo, por exemplo, criar um produto alinhado às atividades, medos e sonhos (Fernandes, 2007). De acordo com Vyncke (2002), o conceito de "estilo de vida" tem sido muito proeminente e fecundamente utilizado em processos de comunicação de marketing. Segundo o autor, a tipologia AIO envolve conceitos mais gerais e estáveis de valores, além de explorar estilos estéticos e visões de vida, o que favorece a utilização deste modelo especialmente em alguns segmentos, como o mercado de mídia (programas de televisão, filmes e revistas), por exemplo. 


\section{Segmentação psicográfica pelos valores.}

Cabe registrar que as pessoas nem sempre se comportam de acordo com seus valores. O comportamento também sofre influência de variáveis demográficas, geográficas, socioeconômicas e fatores externos. Isso posto não é confiável inferir os valores de uma pessoa por meio de seus comportamentos. Um indivíduo pode ter certos valores, mas apresentar comportamento contraditório a eles em determinadas situações. Portanto, um comportamento não representa, necessariamente, uma atitude ou valor (Yanaze, 2007).

Em contraponto ao conceito supracitado, esclarece-se que, ao se analisar o tecido social, é possível identificar conjuntos de opiniões similares que possibilitam prever atitudes e comportamentos, visto que expressam valores subjacentes compartilhados por grandes segmentos de população. Sendo assim, os seres humanos podem compartilhar valores semelhantes, em que, as diferenças de opinião derivam do grau de importância que se atribui a tais valores (Gastaldello, 1999).

O estudo dos valores pessoais dos indivíduos tem sido concretizado por meio de várias metodologias. Dentre elas, destacam-se três metodologias que tem sido utilizadas com frequência ou abordadas conceitualmente em trabalhos científicos: Rokeack Valey Survey - RVS, Values and Lifestyle Segmentation - VALS (atualmente VALS 2) e List of Values - LOV.

Milton Rokeach foi pioneiro na investigação acerca da natureza dos valores humanos com vistas a compreender o comportamento de consumo. Ele desenvolveu um importante instrumento para sua medição que se tornou conhecido como Rokeach Value Survey - RVS (Cardoso \& Costa, 2008). A pesquisa pelo RVS institui que existe uma dinâmica de alterações entre os valores em determinados segmentos sociais, sendo que ocorre uma hierarquia desses valores, que se estabelece de acordo com as variações socioeconômicas, idade, sexo, religião e estilos de vida. Assim, o RVS entende que, por meio dos valores, que são suscetíveis às influências de outras variáveis, as pessoas tendem a conferir uma ordenação de importância aos seus objetivos e formas de comportamento (Miniard et al., 2005, Yanaze, 2007).

Outra escala de valores, entre as mais utilizadas, trata-se do Values and Lifestyle Segmentation - VALS. Como o próprio termo indica, é uma abordagem ao estilo de vida, 
mas que também utiliza um sistema de valor baseado em teorias. $\mathrm{O}$ conceito original foi desenvolvido por uma empresa de consultoria, denominada SRI (Stanford Research Institute), em 1978. Foi baseado no cruzamento entre várias teorias, como por exemplo, a Hierarquia de Necessidades de Maslow com o conceito de característica social (inner/ outerdirected), de Riesman, Glazer e Denney. No questionário de pesquisa VALS, ao invés de utilizar, de forma pragmática, os atributos obtidos dos valores daquilo que está se estudando (por meio de análise fatorial e outros métodos), a opção é pelo uso de atributos gerais que são firmados pelas teorias de valores previamente definidas (Yanaze, 2007).

Em sua concepção inicial, o sistema VALS apresentou falhas de execução. O programa original foi baseado em como os consumidores concordavam e discordavam com declarações temáticas, identificando a princípio, nove estilos de vida americanos (a pesquisa VALS foi implantada nos Estados Unidos, patrocinada por 39 empresas norte-americanas que tinham interesse pela ferramenta). O problema era que, ao se aplicar a pesquisa, a maioria dos consumidores era classificada somente dentro de duas categorias, o que reduzia a importância das demais. Nas aplicações de campo, à medida que os consumidores começavam a concordar com os temas sociais medidos, os resultados se tornavam menos indicativos do comportamento (Melo, 2013, Miniard et al., 2005).

Ao considerar dificuldades encontradas no VALS, em 1989 foi concebido o VALS 2. Nessa versão, as pessoas passam a ser tipificadas na forma como gastam seu tempo e dinheiro, baseadas em duas dimensões - a auto-orientação e os recursos. A primeira dimensão, auto-orientação do consumidor, é regida por três orientações: Princípios (decisões de compra a partir de crenças e princípios dos consumidores); Status (influências pelas crenças, opiniões e ponto de vista dos outros); Ação (consumo para causar impacto no mundo à sua volta). A segunda dimensão, dos recursos, refere-se ao quanto os consumidores são dispostos conforme a quantidade e variedade de meios materiais, psicológicos e demográficos de que dispõem, incluindo fatores como renda, educação, saúde, níveis de energia e vontade de comprar. Em 2001, o VALS 2 ainda sofreu nova modificação, passando a ser chamado informalmente de VALS 2.3 (Yanaze, 2007, Samara \& Morsch, 2005, Miniard et al., 2005).

Existem oitos segmentos de consumidores estabelecidos pelo VALS 2: inovadores (pessoas bem sucedidas, sofisticadas e ativas); reflexivos (pessoas maduras e flexíveis, que 
valorizam a ordem e a responsabilidade); realizadores (orientados ao sucesso de carreira com recompensas materiais); experimentadores (jovens, rebeldes e que experimentam o novo); crentes (conservadores, comprometidos com a família, religião, comunidade e nação); esforçados (buscam auto-afirmação, inseguros); fazedores (pessoas práticas que valorizam a autossuficiência); lutadores (pobres, com pouco estudo e habilidades, mais velhos, preocupados com a saúde) (Campomar \& Gil, 2006).

Outra classificação da VALS 2 segue disposta na Figura 1:

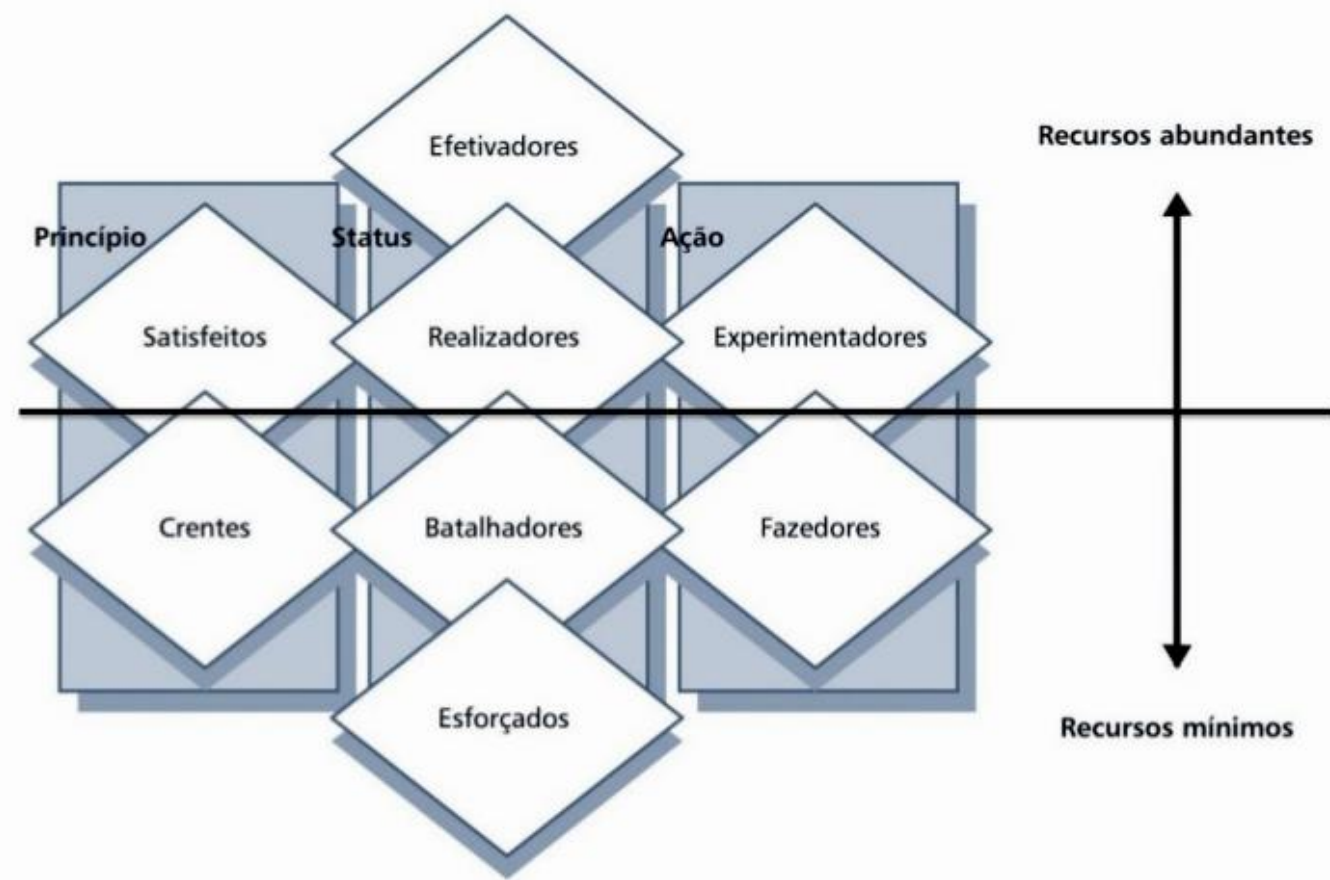

Figura 1

Fonte: Samara e Morsch (2005)

Não obstante o VALS 2 ter tido ampla aceitação e utilização, o sistema possui limitações. Em primeiro, na avaliação quanto ao estilo de vida dos consumidores, alguns resultados parecem apontar necessidade de maior precisão. Em segundo, por ser uma base de dados privada, os pesquisadores acadêmicos podem não se sentir confortáveis com a confiabilidade e a validade das informações recolhidas pelo VALS. Em terceiro, o VALS é criticado por estar fortemente embasado em dados demográficos e também por possuir questões que tem viés da cultura norte-americana, supondo ser de difícil aplicação fora dos Estados Unidos (Kahle \& Kennedy apud Campomar \& Gil, 2006, Miniard et al., 2005). 
Conforme estabelecem Baker et al. (2004), normalmente, dentro de uma cultura, a maioria dos membros concorda com os valores que são importantes para eles, sendo assim, entre culturas de diferentes localidades poderá haver grandes diferenças.

Uma alternativa ao VALS 2 é a abordagem da Lista de Valores (List of Values - LOV). O LOV constitui uma adaptação de parte dos valores abordados pela RSV (Rokeach Value Scale). Pela pesquisa de Kahle, que concebeu o método, propôs-se a LOV como uma escala mais reduzida que a RSV, portanto, um modelo simplificado e mais fácil de ser aplicado (Kahle et al., 1986). O objetivo da escala LOV é avaliar os valores dominantes de uma pessoa. Um ponto importante a frisar é que a LOV não engloba todas as dimensões costumeiramente presentes num inventário psicográfico, faltando a abordagem aos estilos de vida, originalmente concebida no método AIO. Sendo assim, quando a LOV é utilizada para pesquisas de mercado, deve-se aplicar uma avaliação em paralelo dos perfis demográficos dos entrevistados, adicionado essa avaliação às questões de valor pré-definidas na escala. (Mowen \& Minor, 2006, Miniard et al., 2005).

A escala LOV considera os seguintes valores: 1. Auto-realização; 2. Entusiasmo; 3. Senso de realização; 4. Respeito a si mesmo; 5. Senso de pertinência; 6. Ser respeitado; 7. Segurança; 8. Diversão e entretenimento; 9. Relações afetuosas com outras pessoas (Mowen \& Minor, 2006).

Alguns estudos indicam que a escala LOV tende a apresentar algumas vantagens em relação à VALS 2. Pesquisadores ao compararem a VALS 2 e a LOV, descobriram que a LOV, quando acrescida dos dados demográficos, consegue predizer melhor o comportamento do consumidor que a VALS 2. E ainda, quando são adicionadas à LOV outras medidas gerais de valores afora os existentes dessa escala, por exemplo - o materialismo, o poder preditivo ainda se torna maior (Miniard et al., 2005).

Mesmo renovada em relação à primeira versão, permaneceu na VALS 2 a limitação em ter sido formulada a partir da influência do estilo de vida americano. Em uma pesquisa realizada considerando a cultura japonesa, foi indicado que a LOV pode ser mais constante nos resultados que a VALS 2, ao se inserir tais metodologias em diferentes culturas. Alguns autores indicam que as influências dos significados culturais tem interferência no resultado final de aplicação da LOV, sendo importante a aplicação complementar de uma pesquisa 
qualitativa, afim de melhor compreender os resultados encontrados (Watkins \& Gnoth como citado em Campomar \& Gil, 2006).

Kahle et al. (1986) e Novak e MacEvoy (1990) desenvolveram testes empíricos comparativos entre os métodos VALS e LOV. Em ambas as pesquisas, os resultados indicaram que os dois métodos apresentam eficácia quanto a atingir um valor preditivo significativo, entretanto, tal circunstância somente ocorreu nas etapas em que os testes empregaram o uso da escala LOV precedida da inclusão de variáveis demográficas do público amostrado.

\section{Segmentação psicográfica pela personalidade.}

Na pesquisa psicográfica, os traços de personalidade se analisados isoladamente, sem a composição com outras variáveis, possuem pouco poder preditivo acerca do comportamento de consumo. Principalmente, por vários dos estudos de personalidade terem sido conduzidos sob a ótica da psicologia clínica, sem contemplarem a interface com outras dimensões de comprovada importância na segmentação psicográfica. Sendo assim, durante certo período, as pesquisas nesse sentido permaneceram inertes. São escassos os estudos contemporâneos sobre a relação entre a personalidade e consumo (Monteiro et al., 2008).

Vários estudos feitos por pesquisadores que empregam abordagem às características de personalidade são fracos e não conclusivos. Muitas dessas pesquisas identificam um grande número de características, que não estão reunidas num princípio organizador subjacente. Mas, em 2000, John Mowen desenvolveu uma nova abordagem para se compreender os traços no comportamento consumidor. Essa é denominada "modelo 3M de motivação e personalidade”. Tal método procura fornecer uma estrutura organizada ao entendimento, visando compreender a maneira como os traços influenciam o comportamento. A sigla 3M significa "modelo metateórico de motivação" (Mowen \& Minor, 2006).

Mowen apresenta em sua obra argumentos e sólida evidência empírica que de fato é possível prever comportamentos de consumo a partir de traços da personalidade. O modelo 3M representa uma metateoria, quer dizer, uma teoria que agrega diversas teorias de médio 
alcance da psicologia e que ultrapassa o potencial explicativo e conceitual de cada teoria isoladamente. Dessa forma, o modelo $3 \mathrm{M}$ segue com o intuito de avaliar essa relação de forma mais abrangente e com maior potencial de aplicação prática que os estudos anteriores. A metateoria que envolve o método $3 \mathrm{M}$ integra a hierarquização dos modelos de traços de personalidade com princípios da psicologia evolucionista (Monteiro et al., 2008, Monteiro \& Veiga, 2009, Monteiro et al., 2009, Mowen, 2000). O modelo 3M identifica quatro níveis de traços, numa sequência hierarquicamente disposta: traços superficiais, traços situacionais, traços compostos e traços elementares. No nível mais concreto estão os traços superficiais, que são definidos como uma disposição duradoura para agir dentro dos domínios específicos do contexto. Por exemplo, uma tendência íntima contínua em exercer compra compulsiva (Mowen \& Minor, 2006).

No segundo nível de abstração estão os traços situacionais, definidos como uma disposição duradoura para agir dentro de contextos situacionais gerais. Por exemplo, ter expressão de interesse por esportes em geral ou a propensão por produtos tecnológicos. No modelo $3 \mathrm{M}$, os traços situacionais se originam da interação do contexto situacional com as características de personalidade mais básicas (Mowen \& Minor, 2006). Entende-se que, a relação dos traços situacionais pode ser associada a traços de personalidade profundos: “[...] os traços situacionais que as pessoas exibem, tais como a tendência de um estilo de vida saudável [...], podem ser associados a traços de personalidade mais profundos [...]“ (Monteiro et al., 2008, p. 31).

Os dois níveis restantes de traços concernentes ao modelo 3M são os traços elementares e os traços compostos. Os traços elementares são definidos como predisposições psicológicas subjacentes mais básicas dos indivíduos, resultantes do histórico genético e da aprendizagem precoce. Sendo assim, os traços elementares são considerados como modalidade de traços psicológicos básicos do indivíduo. $\mathrm{O}$ modelo $3 \mathrm{M}$ trabalha com oito traços: 1. Abertura à experiências; 2. Consciência; 3. Extroversão; 4. Amabilidade; 5. Neurotização; 6. Necessidades Materiais; 7. Necessidades de Excitação; 8. Necessidades físicas/ de recursos corporais (Mowen \& Minor, 2006). De acordo com Fang e Mowen (2009), os oito traços apresentados são a composição entre o modelo dos cinco fatores, desenvolvido por Gerard Saucier em 1994, com outros traços extraídos da psicologia evolucionista. 
Os traços compostos, os quais também constituem uma linha de traços psicológicos básicos, são definidos como predisposições que resultam dos efeitos dos traços elementares, mas de forma integrada ao aprendizado de uma pessoa e do ambiente cultural. A partir de tais variáveis, propõe-se a existência de alguns traços compostos, dentre os quais, destacamse a autoeficácia, a competitividade e a necessidade de atividade (Mowen \& Minor, 2006). Fang e Mowen (2009) destacam que os traços compostos são situacionais, resultantes de múltiplos efeitos dos traços elementares associados ao processo de socialização do indivíduo. Um esboço esquemático do modelo 3M pode ser observado na figura 2.

Hierarquia dos traços

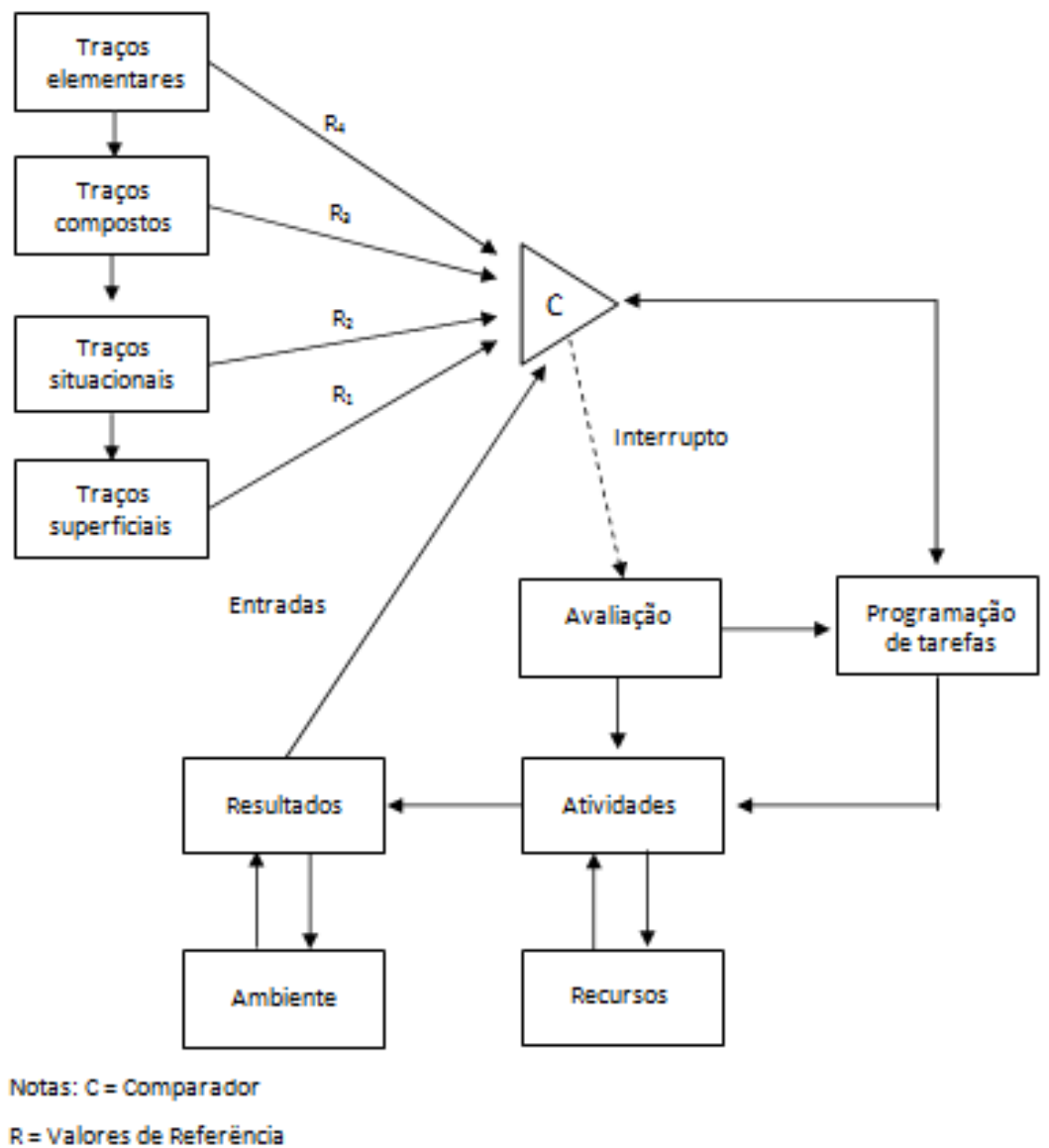

Figura 2

Fonte: Mowen (como citado em Monteiro et al., 2008).

Registra-se a realização de uma pesquisa pela teoria $3 \mathrm{M}$ junto a graduandos em administração, a qual visava entender como ocorre no consumo a relação entre a 
personalidade do indivíduo e sua lealdade, buscando identificar relacionamentos diretos entre os constructos dentro de uma estrutura hierárquica de personalidade. No estudo, foi verificado que a lealdade pode ser precedida pelos traços de personalidade, em que, no modelo 3M, a relação mostrou um caminho significativo partindo de disposições mais abstratas da personalidade (traços elementares), passando pela autoeficácia (traço composto), que conduz a satisfação e confiança (traços situacionais), que, diretamente, explicam a lealdade (traço superficial) (Basso, 2008).

\section{Método}

\section{Coleta de Dados}

O objetivo do estudo é dispor a discussão ao constituir um instrumento comparativo da segmentação psicográfica por meio da confrontação de seus modelos, o qual seja útil em facilitar as decisões metodológicas das pesquisas de comportamento do consumo. Sendo assim, o estudo realizado foi baseado na revisão de literatura (Marconi \& Lakatos, 2010) e tem sua fundamentação obtida em publicações nacionais e estrangeiras voltadas ao assunto proposto. Parte do levantamento bibliográfico foi realizada em plataformas de buscas acadêmicas: Google Acadêmico, Spell, Scielo e Ebsco; e foram utilizados alguns livros específicos sobre o tema. Quanto ao critério de seleção das publicações utilizadas, optou-se, a princípio, por adotar os estudos nacionais contidos nas bases de dados disponíveis, visto que a literatura indica que fatores culturais podem influenciar em alguns métodos psicográficos, e, portanto, empregou-se como primeiro foco desta pesquisa observar os testes empíricos já realizados no mercado nacional. Ressalta-se que, num segundo momento, também se procedeu uma seleção de pesquisas internacionais, tendo por critério de escolha a adoção de alguns autores de renome nos temas em questão, tendo estes empregado testes empíricos nos mercados europeu e norte americano. A utilização de tais trabalhos visa não só conceder o embasamento teórico necessário ao referencial literário, mas ainda, acessar a experiência de pesquisas em mercados externos. 


\section{Análise de Dados}

A análise dos dados se deu por meio da constituição de um quadro-resumo comparativo das principais técnicas psicográficas. $\mathrm{O}$ esquema sintético compara criticamente as aplicabilidades e limitações em cada um dos métodos estudados, apontando vantagens e desvantagens desses conforme o contexto. Tal expediente concede caráter inovador ao estudo, visto que, entre os constructos considerados (estilos de vida, valores e personalidade), não se encontraram nos bancos de dados utilizados, artigos que disponibilizassem simultaneamente considerações críticas comparativas dos principais métodos psicográficos que envolvem tais constructos, exceto de modo incipiente ou por mera alusão ao termo.

\section{Discussão de Resultados}

\section{Implicações para a teoria}

Após análise dos dados por base teórica, os autores estabeleceram critérios de avaliação para comparação dos métodos de análise psicográfica, tendo em conta particularidades do processo de segmentação, constituindo o quadro comparativo a seguir:

\begin{tabular}{|c|c|c|c|}
\hline & BASES CONCEITUAIS & APLICAÇÕES DO MODELO & CONSIDERAÇÕES CRÍTICAS \\
\hline AIO & $\begin{array}{l}\text { A análise por estilo de vida } \\
\text { tem por base uma visão } \\
\text { sociológica, não se fixando } \\
\text { nas variáveis que se dão na } \\
\text { intimidade da formação } \\
\text { psicológica do indivíduo. } \\
\text { Ao contrário, tal modelo } \\
\text { se pauta nas influências do } \\
\text { meio externo sobre os } \\
\text { seres humanos, atingidos } \\
\text { por forças econômicas, } \\
\text { culturais e sociais, capazes } \\
\text { de impactar no } \\
\text { comportamento de } \\
\text { indivíduos vinculados a } \\
\text { grupos. }\end{array}$ & $\begin{array}{l}\text { O modelo AIO se constitui numa } \\
\text { ferramenta útil aos gestores de } \\
\text { marketing que decidam } \\
\text { segmentar produtos alinhados } \\
\text { aos interesses e visões de grupos } \\
\text { comuns. Por exemplo, uma } \\
\text { categoria de pessoas que opte } \\
\text { por um estilo de vida saudável } \\
\text { (as influências de grupo podem } \\
\text { transcender características } \\
\text { individuais de personalidade). }\end{array}$ & $\begin{array}{l}\text { A dificuldade na adoção do } \\
\text { modelo se dá pelo } \\
\text { embasamento em algumas } \\
\text { variáveis muito generalistas, } \\
\text { tais como estágios do ciclo de } \\
\text { vida, renda e educação, } \\
\text { limitadas ao segmentar } \\
\text { mercados em grandes blocos. } \\
\text { Sendo assim, em nosso } \\
\text { entendimento, o modelo AIO } \\
\text { pode apresentar restrições na } \\
\text { composição de segmentos de } \\
\text { menor porte, os quais devam } \\
\text { demandar estudo de } \\
\text { características do } \\
\text { individualizadas e detalhadas }\end{array}$ \\
\hline
\end{tabular}




\begin{tabular}{|c|c|c|c|}
\hline & & & dos consumidores. \\
\hline RSV & $\begin{array}{l}\text { O modelo de Rokeach foi } \\
\text { precursor na consideração } \\
\text { dos valores humanos, } \\
\text { ainda válido aos dias } \\
\text { atuais. Considera que os } \\
\text { grupos sociais se pautam } \\
\text { em valores que se } \\
\text { alternam em ordem de } \\
\text { importância conforme as } \\
\text { dinâmicas sociais. }\end{array}$ & $\begin{array}{l}\text { A utilidade do modelo está no } \\
\text { embasamento pelos valores, os } \\
\text { quais constituem estruturas } \\
\text { centrais da personalidade. Os } \\
\text { valores individuais e sociais são } \\
\text { centrais na vida das pessoas, } \\
\text { representando crenças sobre a } \\
\text { vida e os comportamentos. Dessa } \\
\text { forma, tal modelo será útil na } \\
\text { segmentação de produtos que } \\
\text { demandem certas disposições } \\
\text { ideológicas, como o mercado de } \\
\text { moda, por exemplo. }\end{array}$ & 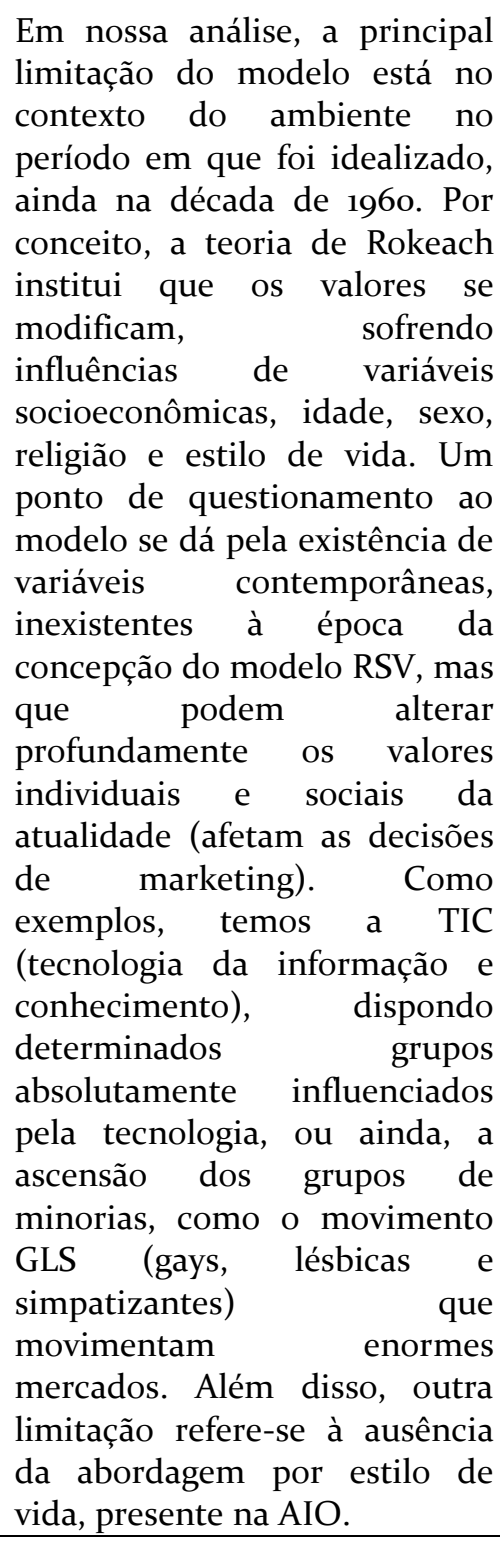 \\
\hline VALS & $\begin{array}{l}\text { Representa um modelo } \\
\text { mais completo, ao adotar } \\
\text { simultaneamente uma } \\
\text { abordagem que contempla } \\
\text { os estilos de vida e sistema } \\
\text { de valores. Combina o } \\
\text { cruzamento de diversas } \\
\text { teorias e considera vários } \\
\text { fatores, como princípios } \\
\text { pessoais, status e } \\
\text { disponibilidade de } \\
\text { recursos. O modelo } \\
\text { estabelece oito categorias } \\
\text { de consumidores: } \\
\text { inovadores, reflexivos, } \\
\text { realizadores, }\end{array}$ & $\begin{array}{l}\text { A vantagem do modelo se dá } \\
\text { pela segmentação por meio da } \\
\text { categorização de consumidores, } \\
\text { o que no mínimo, incita aos } \\
\text { gestores de marketing uma } \\
\text { reflexão acerca dos diversos } \\
\text { perfis de consumo, podendo ser } \\
\text { útil em variadas situações na } \\
\text { composição de produtos e } \\
\text { serviços. }\end{array}$ & $\begin{array}{l}\text { A grande limitação do modelo } \\
\text { se dá por seus viés cultural. } \\
\text { Como o VALS foi concebido } \\
\text { nos Estados Unidos, levando } \\
\text { em consideração fatores } \\
\text { demográficos do povo norte- } \\
\text { americano, por mais que tenha } \\
\text { passado por modificações e } \\
\text { melhoramentos ao longo de } \\
\text { seu curso, possui limitações ao } \\
\text { ser empregado em culturas fora } \\
\text { dos EUA. }\end{array}$ \\
\hline
\end{tabular}




\begin{tabular}{|c|c|c|c|}
\hline & $\begin{array}{l}\text { experimentadores, } \\
\text { crentes, } \quad \text { esforçados, } \\
\text { fazedores e lutadores. }\end{array}$ & & \\
\hline LOV & $\begin{array}{l}\text { Trata-se de uma adaptação } \\
\text { teórica que considera os } \\
\text { valores abordados pela } \\
\text { RSV, mas em formato de } \\
\text { escala mais reduzido, num } \\
\text { modelo simplificado e } \\
\text { mais fácil de ser aplicado. } \\
\text { O modelo estabelece os } \\
\text { seguintes valores: 1. Auto- } \\
\text { realização; 2. Entusiasmo; } \\
\text { 3. Senso de realização; } 4 . \\
\text { Respeito a si mesmo; } 5 . \\
\text { Senso de pertinência; } 6 . \\
\text { Ser respeitado; } 7 \text {. } \\
\text { Segurança; } 8 \text {. Diversão e } \\
\text { entretenimento; } \\
\text { Relações afetuosas com } \\
\text { outras pessoas. }\end{array}$ & $\begin{array}{l}\text { A aplicação da LOV ocorre nos } \\
\text { mesmos termos que a RSV, em } \\
\text { situações que seja vantajoso aos } \\
\text { gestores de marketing } \\
\text { compreender em profundidade } \\
\text { os valores do mercado estudado. }\end{array}$ & $\begin{array}{l}\text { A limitação é que o modelo } \\
\text { demanda uma avaliação em } \\
\text { paralelo dos } \\
\text { demográficos } \\
\text { entrevistados, adicionando essa } \\
\text { avaliação às questões de valor } \\
\text { pré-definidas na escala. E } \\
\text { ainda, tal como na RSV, } \\
\text { também falta abordagem aos } \\
\text { estilos de vida. }\end{array}$ \\
\hline $3 \mathbf{M}$ & 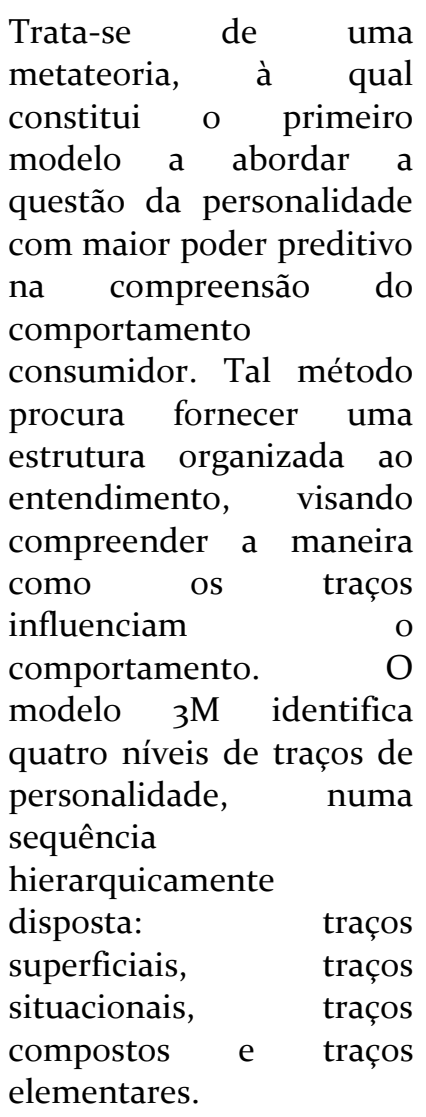 & $\begin{array}{l}\text { A vantagem do modelo está em } \\
\text { sua concepção metateórica, ou } \\
\text { seja, uma teoria que agrega } \\
\text { diversas teorias de médio alcance } \\
\text { da psicologia e que ultrapassa o } \\
\text { potencial explicativo e conceitual } \\
\text { de cada teoria isoladamente. } \\
\text { Sendo assim, o modelo 3M pode } \\
\text { ser útil em situações que exijam } \\
\text { uma segmentação que } \\
\text { especifique certas condições que } \\
\text { permeiem os critérios de decisão } \\
\text { do consumidor, com potencial de } \\
\text { identificar ar algumas } \\
\text { predisposições em seu } \\
\text { comportamento. }\end{array}$ & $\begin{array}{l}\text { Quanto às limitações do } 3 \mathrm{M} \text {, o } \\
\text { modelo indica que os quatro } \\
\text { níveis de traços sofrem em suas } \\
\text { estruturas certas influências, } \\
\text { parte delas possivelmente } \\
\text { concernentes aos estilos de } \\
\text { vida e valores, dentro do } \\
\text { composto da personalidade, o } \\
\text { que representa ser uma } \\
\text { abordagem consistente. Sendo } \\
\text { assim, por ora, cabe aguardar a } \\
\text { validação de novos modelos } \\
\text { que também contemplem a } \\
\text { personalidade, para que esses } \\
\text { possibilitem a realização de } \\
\text { testes comparativos, apontando } \\
\text { assim possíveis lacunas. }\end{array}$ \\
\hline
\end{tabular}

\section{Quadro 1}

Fonte: Elaborado pelos autores. 


\section{Implicações para a prática}

O quadro sintético comparativo, ao apresentar o resumo das bases conceituais que compõem os principais modelos de segmentação, amparado pela apreciação dos resultados empíricos dos artigos pesquisados, bem como o processo da observação direta de mercado pelos autores deste artigo, em termos práticos, viabiliza fornecer indicações de circunstâncias em que os métodos psicográficos possam ser mais bem aplicados, propiciando melhor alinhamento desses aos objetivos das pesquisas de marketing. A partir disso, o estudo desenvolvido resulta em recomendações de bases para segmentação psicográfica, fornecendo critérios para utilização dos modelos:

\section{Recomendações de bases para segmentação (1): aplicação de modelo baseado} em análise por estilo de vida (A.I.O.).

O modelo A.I.O. possui natureza abrangente, mais próximo dos critérios demográficos (Samara \& Morsch, 2005). Por tal característica, se deduz que a aplicação do A.I.O. viabiliza segmentação em grandes grupos, tanto produtos commodities como os de características regionais (preferências locais). Alguns são segmentos mais sensíveis à variável preço e estão na base da pirâmide (Maslow, 1968), porém, nem sempre ocorre assim. Há grandes mercados com alto valor agregado passíveis de emprego do método A.I.O. Esses podem se dar em consumidores com comportamentos baseados numa diretriz primária de vida comum, tal como o mercado fitness, ou linhas de produtos light e diet.

O modelo A.I.O. pode ser útil em explorar transformações do macroambiente, quer sejam culturais ou socioeconômicas. Um exemplo é o segmento de farinha para tapioca, produto típico da cultura nordestina, com aumento de consumo na região sudeste. Tal transformação advém do crescimento do turismo experimentado nas últimas décadas, com gradativa absorção da cultura regional, a gerar demanda por novos produtos. Outro exemplo se dá pelo aumento do poder de consumo das classes $C$ e $D$ nos últimos anos. A indústria de eletrodomésticos estabeleceu um novo e grande segmento de mercado, ao exercer uma política de crédito específica para explorar tal público, o qual tem como interesse e objetivo 
comuns o aumento do conforto doméstico. O A.I.O., por característica, se apresenta mais comum em grandes mercados, visto que segmentos menores ou nichos podem ser mais sensíveis às nuances individuais dos consumidores. Mas podem ocorrer exceções em mercados de pequeno porte, desde que esses tenham membros com interesses comuns suficientemente fortes para promover agrupamento. Um exemplo se dá no mercado de aeromodelismo, que embora de tamanho reduzido, possui membros com características socioeconômicas próximas e de forte atração comum por essa atividade de hobbie. Como regra, o A.I.O. aplica-se a mercados em que os componentes sociológicos são determinantes na escolha individual, pois nesses casos os consumidores terão motivação maior por influências do meio social, se sobrepondo à parte de suas inclinações íntimas. Tal premissa deve servir como "bússola" aos optantes da adoção deste modelo, logo após definirem os objetivos de sua pesquisa.

\section{Recomendações de bases para segmentação (2): aplicação de modelos} baseados em valores (RSV, VALS, LOV).

Os modelos condizentes a exploração dos valores apresentam abordagens a partir de diferentes composições. De um lado, têm-se os modelos RSV e LOV, que buscam explorar valores básicos à conduta dos indivíduos; de outro, o modelo VALS (2), que se utiliza dos valores humanos realizando projeções arquetípicas dos indivíduos, formando assim, categorias de consumidores (inovadores, reflexivos, realizadores, experimentadores, crentes, esforçados, fazedores e lutadores).

O RSV parte da escala de valores de Milton Rokeack, presente ainda nos dias atuais (Miniard et al., 2005). A vantagem deste modelo é basear-se em valores fundamentais à sociedade ocidental (desde a Grécia antiga), os quais permanecem. O RSV é útil às pesquisas que se baseiem na identificação de valores essenciais como influência às tendências de consumo. Como exemplo, a campanha de marketing intitulada "outubro rosa" (câncer de mama), que remete ao valor de solidariedade. Ou ainda, produtos que ressaltam valores de um sentido da existência, ou promessa de vida eterna, como artigos religiosos. Há também exploração de valores mais instrumentais, quer dizer, ligados a um estilo de conduta, tal como o consumo de produtos "verdes", valorizando a responsabilidade social. A limitação do 
RSV se dá pela época de sua concepção, ainda a década de 1960, pois há visões que podem ter se alterado ao longo de meio século, com novo significado de alguns valores, por exemplo, o conceito de ser liberal. Há de se destacar vários movimentos sociais transcorridos, como questões de gênero e preferência sexual, ou ainda, macrotransformações tecnológicas, como as redes sociais, com influências à forma como as pessoas se relacionam e, por conseguinte, podendo interferir ao que valorizam. O método RSV, por conceito, reconhece que os valores são suscetíveis aos fatores ambientais. Mas ainda assim é um modelo produtivo em explorar valores básicos que compõem a idealização humana.

Quanto ao método LOV, esse se dá pela simplificação do modelo RSV, resumido e organizado em cerca de metade da quantidade de itens na base dos valores humanos, o que favorece operacionalmente o processo de coleta de dados (Cardoso \& Costa, 2008). O princípio deste método é basicamente o mesmo do anterior, porém mais eficiente em termos de aplicação. Entretanto, o RSV poderá ter mais valia caso se apresente necessária uma maior especificação entre os valores, conforme objetivo de pesquisa que se queira atingir.

Por fim, o modelo VALS (2), o qual apresenta vantagem de um método a partir do cruzamento de diversos conceitos, agregando os estilos de vida às teorias acerca dos valores. Como expediente tal modelo determina perfis de consumidores por meio de projeções arquetípicas (inovadores, reflexivos, realizadores, experimentadores, crentes, esforçados, fazedores e lutadores). É importante ressaltar que na VALS (2) os valores empregados na escala são importantes e universais, entretanto, estes não englobam a totalidade dos valores a se explorar nos meios de consumo. Um exemplo se dá pela pesquisa de Richins e Dawson (1992), que realizaram um amplo estudo com o objetivo de validar medidas a fim de mensurar as orientações de consumo voltadas à característica do materialismo.

No clássico artigo de Hugh Cannon, do ano de 1982, intitulado "Um novo método para estimar o efeito do contexto na mídia”, ainda àquela época o autor já atentava para a importância das campanhas publicitárias serem orientadas pelos valores, e, assim, criativamente vincularem as mensagens de propaganda a certos contextos, explorando a semelhança entre determinados valores e as orientações de anúncios nos meios de comunicação. Têm-se como exemplo, as clássicas campanhas de mídia das marcas de 
cigarros das décadas de 1980 e 1990 exibidas no Brasil, como "o homem selvagem de Malboro", representado pelo típico cowboy americano (fazedores, lutadores), ou a propaganda de jovens audaciosos praticando esportes radicais, da marca Hollywood (experimentadores, inovadores), dentre outras. A limitação do modelo VALS (2), conforme Miniard et al. (2005), é justamente a forte base no modo de vida norte americano, visível em diversas mídias e conceitos de produtos. Mas, mesmo assim, a utilização dos arquétipos individuais gera elevadas cifras ao emprego das segmentações de marketing. Basta observar a indústria cinematográfica, que por meio da persona de vários super-heróis e vilões (identificados aos valores humanos) das marcas Marvel e DC Comics, explora um imenso número de produtos temáticos associados ao público infanto-juvenil, e ainda, outras marcas com exploração de personagens infantis. Dessa forma, a recomendação de segmentação para este modelo se dá nos casos em que seja vantajoso explorar imagens de indivíduos ou personagens formadores de opinião, face ao estilo de vida assumido pelos mesmos em associação dos valores aos quais representam.

\section{Recomendações de bases para segmentação (3): aplicação de modelo baseado} em personalidade $(3 \mathrm{M})$.

$\mathrm{O}$ modelo $3 \mathrm{M}$ conta com a vantagem de ser uma metateoria, a qual prescreve quatro diferentes níveis de traços de personalidade, considerando dentro desses variáveis advindas de outras fontes de influências, como contextos situacionais e ambiente cultural (Monteiro et al., 2008). Sendo assim, o método conta com uma abordagem mais completa, diferente dos testes comuns de personalidade, pois é capaz de mensurar o impacto de certos estímulos externos às predisposições de comportamento (Basso, 2008). Por este motivo o modelo é útil ao exercer pesquisas de segmentação que demandem vincular a relação entre traços de personalidade com comportamentos básicos individuais. Uma utilização da pesquisa $3 \mathrm{M}$ pode se dar, por exemplo, em pesquisas de marketing político, em que se necessite entender quais estímulos externos (premissas e imagem do candidato) são primordiais para intervir no processo decisório do eleitorado. Por via de regra parte de tais pesquisas são realizadas de forma qualitativa (técnica focus group), entretanto, se houver cruzamentos com testes objetivos do $3 \mathrm{M}$, é possível dispor de maior precisão dos resultados. 
Apesar do potencial preditivo deste modelo, destaca-se que a fonte do comportamento humano é multifatorial. Portanto, assevera-se que nem sempre os indivíduos apresentam atitudes condizentes com suas predisposições comportamentais de personalidade, o que deve ser observado.

\section{Conclusões}

Atualmente, verifica-se que várias empresas de consultoria cometem erros na aplicação de técnicas de pesquisa de mercado, ganhando concorrências por meio de preços reduzidos para prestação de serviços, entretanto, "pecando" na qualidade da entrega por não aplicarem adequadamente os modelos teóricos disponíveis, implicando certa improvisação técnica. Algumas dessas constituem modelos de pesquisas ad hoc (sob encomenda), cujos quais não acarretariam problemas caso fossem respeitados mínimos procedimentos cientificamente exigíveis, o que na prática não ocorre. Sendo assim, é fundamental ter um princípio-guia que norteie adequação das técnicas disponíveis, de forma que se possa melhor atender aos objetivos das pesquisas e preservar sua qualidade, além de otimizar o payback sobre as contratações de serviços, ao que o estudo do presente trabalho espera prestar utilidade.

Portanto, do ponto de vista acadêmico, crê-se que a contribuição da presente pesquisa resida na avaliação e comparação dos modelos de segmentação mais discutidos em textos acadêmicos, como estímulo a aplicação de testes empíricos comparativos dos modelos. E, do ponto de vista gerencial, supõe-se que a contribuição esteja baseada na indicação dos contextos de mercado em que cada técnica possa ser empregada de maneira mais eficaz, propiciando às empresas e profissionais de marketing um guia para realização de pesquisas de segmentação de mercado.

\section{Limitações da Pesquisa}

Os resultados da pesquisa remetem à seguinte conclusão: na segmentação psicográfica não há o aclamado "modelo perfeito", tendo em conta que os processos de 
segmentação ocorrem em circunstâncias bastante específicas, que demandam diferentes abordagens.

Como limite dessa pesquisa assevera-se que, a conclusão supracitada parte de uma avaliação calcada em análise essencialmente teórica, em que, não ocorreu a execução de métodos de pesquisa que apresentassem alguma evidência empírica, limitando assim o alcance dos resultados. Para comparação mais efetiva entre os métodos psicográficos, faz-se necessário a coleta e análise de dados primários, preferencialmente pelo cruzamento dos resultados de diferentes escalas psicográficas, tendo ainda em consideração os componentes que envolvem o ambiente de marketing (cultura, economia, política, tecnologia) como variáveis intervenientes a serem consideradas na análise.

\section{Sugestões para Pesquisas Futuras}

Ao considerar as possibilidades das técnicas psicográficas, tem-se a perspectiva de que haja futuros estudos relacionados ao assunto a partir deste trabalho, principalmente pesquisas que apresentem evidências empíricas de comparação dos modelos psicográficos abordados. Pretende-se também por meio da discussão apresentada, estimular o intercâmbio de informações entre o meio gerencial (empresas de pesquisa) e academia, como recurso para suscitar novas pesquisas e aplicações empresariais.

Espera-se ainda que os resultados obtidos venham a servir como guia e fonte de informação a gestores e pesquisadores que se propuserem a empregar métodos psicográficos nas pesquisas de consumo. 


\section{Referências}

Almeida, I. C., Vilas Boas, L. H. D. B., Sette, R. D. S., \& de Oliveira, A. S. (2010). Valores pessoais das mulheres empresárias: aplicação da escala LOV. Revista Brasileira de Marketing, 9(3), 49-68.

Baker, S., Thompson, K. E., Engelken, J., \& Huntley, K. (2004). Mapping the values driving organic food choice: Germany vs the UK. European journal of marketing, 38(8), 995-1012.

Basso, K. (2008). Personalidade e lealdade: uma aplicação do modelo meta-teórico de motivação e personalidade (Modelo 3M). (Dissertação de Mestrado, Administração e Negócios) Pontifícia Universidade Católica do Rio Grande do Sul, Porto Alegre.

Blamey, R. K., \& Braithwaite, V. A. (1997). A social values segmentation of the potential ecotourism market. Journal of Sustainable Tourism, 5(1), 29-45

Campomar, M. C., \& Gil, C. (2006). Analisando VALS como Instrumento de Segmentação. Anais do IX SEMEAD.

Cannon, H. M. (1982). A new method for estimating the effect of media context. Journal of Advertising Research, 22(5), 41-48.

Cardoso, P. R., \& Costa, H. S. (2008). Uma análise dos valores dos jovens consumidores portugueses. Revista da Faculdade de Ciências Humanas e Sociais da Universidade Fernando Pessoa, 5, 128 - 140.

Comerciais antigos de cigarros (1988). Recuperado de https://www.youtube.com/watch?v=LHy7RXJ7W8Y.

Corneo, G., \& Jeanne, O. (1994). A theory of fashion based on segmented communication. Bonn: University of Bonn.

Fang, X., \& Mowen, J. C. (2009). Examining the trait and functional motive antecedents of four gambling activities: Slot machines, skilled card games, sports betting, and promotional games. Journal of Consumer Marketing, 26(2), 121-131 
Finotti, M. A. (2004). Estilos de vida: uma contribuição ao estudo da segmentação de mercado. (Dissertação de Mestrado, Administração) Universidade de São Paulo, São Paulo.

Gastaldello, A. T. (1999). A influência de valores pessoais de executivos brasileiros e argentinos em negociações comerciais. (Dissertação de Mestrado, Administração) Programa de Pós-Graduação em Administração, Universidade Federal do Rio Grande do Sul, Porto Alegre.

Grunert, K. G., Sorensen, E., Johansen, L. B., \& Nielsen, N. A. (1995). Analysing food choice from a means-end perspective. E-European Advances in Consumer Research. (Vol. 2.). Recuperado de http://acrwebsite.org/volumes/11135/volumes/eo2/E-02

Kahle, L. R., Beatty, S. E., \& Homer, P. (1986). Alternative measurement approaches to consumer values: the list of values (LOV) and values and life style (VALS). Journal of consumer research, 13(3), 405-409.

Kasarklian, E. (2004). Comportamento do consumidor. São Paulo: Atlas.

Lawson, R., \& Todd, S. (2003). Repackaging consumer lifestyles. Otago: University of Otago.

Leão, A. L. M. D. S., Souza Neto, A. F. D., \& Mello, S. C. B. D. (2007). Compreendendo os valores das marcas: aplicação da lista de valores em diferentes indústrias. Revista de Administração Contemporânea, 11(2), 27-48.

Marconi, M. D. A., \& Lakatos, E. M. (2010). Fundamentos de metodologia científica. In M. D. A. Marconi, \& E. M. Lakatos. (2010). Fundamentos de metodologia científica. Atlas.

Maslow, Abraham H. (1968). A psicologia do ser. Rio de Janeiro: Eldorado Tijuca.

Medeiros, S. A., \& Dantas, A. de B. (2007). Segmentação Psicográfica Baseada em Valores: um Estudo Exploratório para o Mercado de Cerveja de Maceió. IV Simpósio de Excelência em Gestão e Tecnologia - SEGeT.

Mello, S. C. B. de, Souza Leão, A. L. M. de, \& de Souza Neto, A. F. (2008). Que valores estão na moda? Achados muito além do efêmero. Revista de Administração Mackenzie, 4(2). 
Melo, F. V. S. (2013). Segmentação psicográfica como estratégia educacional: um estudo em instituições de ensino superior. Revista Científica Semana Acadêmica, ano MMXI, oooooz.

Miniard, P. W., Engel, J., \& Blackwell, R. (2005). Comportamento do consumidor. Rio de Janeiro: LTC.

Monteiro, P. R. R., \& Veiga, R. T. (2009). Personalidade e segmentação do mercado de moda: contrastes e perfil de jovens inovadores segundo o gênero. Revista Pretexto, 10(1).

Monteiro, P. R. R., Veiga, R. T. \& Gonçalves, C. A. (2009). Previsão de comportamento de consumo usando a personalidade. RAE-eletrônica, 8(2), 1.

Monteiro, P. R. R., Veiga, R. T., Gosling, M. \& Gonçalves, M. A. (2008). Personalidade e consumo ecologicamente consciente. Revista de Administração FACES Journal, 7(2).

Mowen, J. C. (2000). The $3 M$ model of motivation and personality: Theory and empirical applications to consumer behavior. New York: Springer Science \& Business Media.

Mowen, J. C., \& Minor, M. S. (2003). Comportamento do consumidor. São Paulo: PrenticeHall.

Novak, T. P., \& MacEvoy, B. (1990). On comparing alternative segmentation schemes: The List of Values (LOV) and Values and Life Styles (VALS). Journal of consumer research, 17(1), 105-109.

Richins, M. L., \& Dawson, S. (1992). A consumer values orientation for materialism and its measurement: Scale development and validation. Journal of consumer research, 19(3), 303316.

Robbins, S. P., Judge, T. A., \& Sobral, F. (2012). Comportamento Organizacional: Teoria e prática no contexto brasileiro. São Paulo: Pearson.

Samara, B. S., \& Morsch, M. A. (2005). Comportamento do consumidor: conceitos e casos. São Paulo: Prentice-Hall.

Solomon, M. R. (2007). O comportamento do Consumidor. Porto Alegre: Artmed. 
Tomanari, S. (2003). Segmentação de mercado com enfoque em valores e estilo de vida (segmentação psicográfica): um estudo exploratório (Dissertação de Mestrado, Ciências da Comunicação). Programa de Pós-Graduação em Ciências da Comunicação, Universidade de São Paulo, São Paulo.

Tomanari, S. A., \& Yanaze, M. H. (2001). Desmistificando a segmentação psicográfica. In XXIV Congresso Brasileiro de Ciências da Comunicação. Sociedade Brasileira de Estudos Interdisciplinares da Comunicação.

Vyncke, P. (2002). Lifestyle segmentation: From attitudes, interests and opinions, to values, aesthetic styles, life visions and media preferences. European journal of communication, $17(4), 445-463$

Yanaze, M. H. (2007). Gestão de marketing e comunicação: avanços e aplicações. São Paulo: Saraiva. 